\title{
Editorials
}

\section{New UK General Practice Core Standards for Advanced Serious Illness and End of Life Care}

\section{INTRODUCTION}

In the future, care of the dying will be even more demanding than we already believed. Overall, 160000 more people in England and Wales will need palliative care by 2040 and there is little to suggest that Scotland and Northern Ireland will fare much better. In this editorial, we wish to introduce new UK General Practice Core Standards for Advanced Serious Illness and End of Life Care - or 'Daffodil Standards' (see Box 1). They apply to the care and support of patients with advanced serious illness who have palliative care or end-oflife care needs; they include the support of families and carers. The standards will be piloted at selected practices in spring 2018, with subsequent wider implementation from autumn 2018

\section{BACKGROUND}

By 2040, we had estimated that annual deaths in England and Wales were projected to rise by $25.4 \%$, with the number of people requiring palliative care also growing by 25.0\%, from 375398 to 469305 people per year. That was always going to be a stretch for primary care and community services, but it is worse than that. A recent study by Etkind et al has thrown the morbidity trends observed from 2006 to 2014 into the calculation. The principal drivers of need for palliative care will probably be dementia, set to increase from 59199 to 219409 deaths per year, and cancer also increasing from 143638 to 208636 deaths by 2040 .

The new projections put the increase from 2014 to 2040 at $42.4 \%$. So 161842 more people per year, a total of 537240 , will require palliative care in 2040. ${ }^{1}$ Even this calculation does not take into account the likely increased survival and therefore duration of care that the new comorbidities will generate.

\section{ROLE OF GP AND PRIMARY CARE TEAM}

The need to support training on palliative and end-of-life care in general practice has always been recognised and embraced by GPs, who have participated in national initiatives on end-of-life care since their inception. ${ }^{2}$ GPs still value their central role in delivering care and support to patients and their families facing death at home or in community care facilities. General practice teams also have training and development needs, as practice nurses and other practice staff become involved, alongside community partners such as district nurses, hospice staff, and Macmillan and Marie Curie nurses.

\section{RCGP WORKING WITH MARIE CURIE}

The Royal College of General Practitioners (RCGP) is working with Marie Curie to focus on end-of-life care as a clinical priority in order to promote and enable patientcentred, high-quality palliative and end-oflife care. In 2015, the RCGP, supported by Marie Curie, sent out a national survey to explore the experiences of delivering palliative and end-of-life care in general practice. The response was low, but, of the 561 GPs who responded on such issues as educational needs, delivering care, communication, and 24/7 access, 97\% felt that general practice plays a key role in the delivery of care to people approaching the end of life, and their families. ${ }^{3}$ However, in 2016 a further RCGP survey found that time to care for patients and their families at the end of life' was a top priority for general practice. One GP was quoted:

Special provision needs to be made for this group of patients - they need more time and a flexible proactive approach. Currently they are just squeezed in amongst all the acute care and paperwork in an already full day. It is impossible to give the best possible care in these conditions and can be very frustrating for everyone. ${ }^{4}$

The RCGP has published a paper on personalised care and support planning for people living with a terminal illness, ${ }^{5}$ and a position statement on palliative and end-oflife care, ${ }^{6}$ both of which draw on intelligence from the surveys. Also, in response to the surveys, the RCGP and Marie Curie partnership has developed a network of GP advisors throughout the UK, offering a series of learning opportunities on endof-life care for GPs, including regional and national events.

\author{
Box 1. Daffodil Standards \\ 1. Professional and competent staff \\ 2. Early identification \\ 3. Carer support - pre- and post-death \\ 4. Seamless, planned, coordinated care \\ 5. Assess unique needs of the patient \\ 6. Quality care during the last days of life \\ 7. Care after death \\ 8. General practice being hubs within \\ compassionate communities
}

\section{CARERS AND COMMUNITY}

The RCGP and Marie Curie partnership is championing the development of a compassionate community approach to end-of-life care. It seeks to de-professionalise many aspects of care for people with terminal illness and others affected, such as their families, carers, and friends. As Abel and Kellehear put it:

how can we provide an equitable level of care for all people irrespective of diagnosis and how can we increase the range and quality of non-medical/nursing supportive care in a context of diminishing resources? We argue that an important opportunity and solution can be found by adopting the principles of a public health approach to end-of-life care."

Conventional interventions, implemented by professionals, focused only on the patient, such as palliative care needs assessment, self-management health plans, escalation of treatment care plans, or social prescribing, are only part of the solution. There is the assumption that admissions are mainly caused by pathology, morbidity, and disease, but psychosocial issues that impact on health care in the UK are growing in prevalence and severity. These include social isolation, loneliness, anxiety, depression, and inability to cope with escalating dementia., 89 The advocates of a public health or social medicine approach argue that: 


\section{“... the Daffodil Standards will provide GPs and their teams with an overarching, focused strategy to combine quality improvement within general practice, combined with compassionate community development.}

Care for one another at times of crisis and loss is not simply a task for health and social care services, but it's everyone's responsibility. ${ }^{10}$

Practices are in a good position to understand and balance medical and non-medical needs of our population, and therefore could support compassionate community-style interventions. The concept is to develop community assets to allow people to be cared for by the supportive networks that surround them. However, the question remains whether general practice has the capacity and capability to take a lead, or even participate in this approach.

\section{THE DAFFODIL STANDARDS}

In this context, the RCGP and Marie Curie partnership has developed the UK General Practice Core Standards for Advanced Serious Illness and End of Life Care - or 'Daffodil Standards', which will soon be piloted at selected GP practices throughout the UK. The voluntary Daffodil Standards have been developed in conjunction with a wide range of health and care experts and GP practices; they are evidence based, peer reviewed, and offer a structured approach for practices to improve care for patients at an advanced stage of serious illness or approaching end of life.

They outline eight core domains (see Box 1) in which GP practices can look to attain the highest possible standards to ensure compassionate, safe, and effective care, with free tools to help achieve stepby-step improvements in each area.

\section{HOW PRACTICES CAN EMBRACE THE DAFFODIL STANDARDS}

The RCGP and Marie Curie partnership intend that the Daffodil Standards will provide GPs and their teams with an overarching, focused strategy to combine quality improvement within general practice, combined with compassionate community development. There may be real opportunities for general practice to work in partnership, not only with their registered population but also with the wider local community, to connect and build a public health and social medicine approach to end-of-life care where people most want it, within their own community.

\section{CONCLUSION}

This approach could root general practices even more firmly in the communities they serve and could also encourage our communities to work together with health services, social care, businesses, schools, faith groups, trade unions, clubs, and others around a common cause. This could secure the best possible quality of care for one of the most vulnerable groups in our society, that is, those facing death

It is clearly essential that any new approach to the difficult problems in this field are rigorously tested and evaluated in high-quality trials. Early work on a general practice-based system to enhance carers support indicates the potential to shift palliative and end-of-life care away from hospital. Above all else, we must test its ability to change the quality of experience of people who are dying, as well as the experience of their families, friends, and carers.

The RCGP and Marie Curie partnership began evaluation of the Daffodil Standards pilot in early 2018. To find out more contact Catherine Millington-Sanders.

\section{Catherine Millington-Sanders,}

RCGP and Marie Curie National End of Life Care Clinical Champion, RCGP CIRC, London.

\section{Bill Noble,}

Professor of Community Palliative Care, Sheffield Hallam University, Sheffield.

\section{Provenance}

Commissioned; externally peer reviewed.

\section{Competing interests}

Bill Noble's and Catherine Millington-Sanders's posts are funded by Marie Curie.

DOI: https://doi.org/10.3399/bjgp18X694913

\section{ADDRESS FOR CORRESPONDENCE}

Catherine Millington-Sanders

RCGP CIRC, 30 Euston Square, London, NW1 2FB.

E-mail: c.millington-sandersanhs.net

\section{REFERENCES}

1. Etkind SN, Bone AE, Gomes B. How many people will need palliative care in 2040 ? Past trends, future projections and implications for services. BMC Medicine 2017; 15(1): 102. DOI 10.1186/s12916-017-0860-2

2. Hughes PM, Bath PA, Ahmed N, Noble B. What progress has been made towards implementing national guidance on end of life care? A national survey of UK general practices. Palliat Med 2010; 24(1): 68. DOI: 10.1177/0269216309346591.

3. Mitchell S, Loew J, Millington-Sanders C, Dale J. Providing end-of-life care in general practice: findings of a national GP questionnaire survey. Br J Gen Pract 2016; DOI: https://doi.org/10.3399/bjgp16X686113.

4. Royal College of General Practitioners. News. Overstretched GPs call for more time to meet the needs of their terminally ill patients. 3 Nov 2016. http://www.rcgp.org.uk/news/2016/ november/overstretched-gps-call-for-moretime-to-meet-the-needs-of-their-terminallyill-patients.aspx laccessed 30 Jan 2018).

5. Royal College of General Practitioners. Marie Curie personalised care and support planning. http://bit.ly/2FTajze laccessed 8 Feb 2018).

6. Royal College of General Practitioners. The RCGP position statement on palliative and end of life care. http://bit.ly/2BYJjMB laccessed 8 Feb 2018).

7. Abel J, Kellehear A. Palliative care reimagined: a needed shift. BMJ Supportive Palliat Care 2016; 6(1): 21-26.

8. Singh A, Misra N. Loneliness, depression and sociability in old age. Ind Psychiatry J 2009; 18(1): $51-55$.

9. Sleeman K, Perera G, Stewart R, Higginson IJ. Predictors of emergency department attendance by people with dementia in their last year of life: retrospective cohort study using linked clinical and administrative data. Alzheimers Dement 2018; 14(1): 20-27. DOI: 10.1016/j.jalz.2017.06.2267. Epub 2017 Aug 22.

10. Kellehear A. The Compassionate City Charter. In: Wegleitner K, Heimerl K, Kellehear A (eds). Compassionate communities: case studies from Britain and Europe. Abingdon: Routledge, 2015: 76-87. 